\title{
SENTIDOS Y USOS DEL “MIRAR MAL” COMO EJE DE CONFLICTO ENTRE ESTUDIANTES
}

\section{SENSE AND USES OF "BAD LOOKING” AS AN AXIS OF CONFLICT AMONG STUDENTS}

\author{
Pablo Nahuel di Napoli*
}

Fecha de recepción: 6 de febrero de 2018 - Fecha de aceptación: 26 de junio de 2018

\begin{abstract}
Resumen
En el presente artículo se indaga sobre las prácticas y sentidos que construyen los jóvenes en torno a sus miradas, especialmente a un tipo particular de mirada que constituye un eje constante de conflicto en el espacio escolar: el "mirar mal". En la primera parte se recuperan los aportes teóricos del campo sociológico sobre el rostro y la mirada desde una perspectiva relacional. En la segunda parte se analizan los significados que los estudiantes de educación secundaria le atribuyen al "mirar mal" y qué tipo de prácticas se ligan a ella en el ámbito escolar. El corpus empírico se compone de sesenta entrevistas en profundidad realizadas con jóvenes de dos escuelas medias de gestión estatal de la provincia de Buenos Aires en Argentina. Concluimos que a través de la mirada se ponen en juego diferentes aristas de la individualidad juvenil que los agentes educativos debieran tomar en cuenta al actuar sobre la sociodinámica de los conflictos en el ámbito escolar.

Palabras clave: Jóvenes; Rostro; Subjetividad; Cuerpo; Escuela, Sentidos
\end{abstract}

\begin{abstract}
In this article we look into the meanings that young people build behind the practices of ways of eye gazing, especially to a particular type of gaze that constitutes a constant conflict axis at school: the"bad eye"or "angry stare". In the first part of this article, we recover the theoretical contributions of the sociological field about face and eye gaze from a relational perspective. Secondly, we analyze the meanings that high school students confer to the "bad eye" stare and the type of practices linked to it at academic environments. The empirical corpus consists of sixty in-depth interviews to young from two state high schools in Buenos Aires, Argentina. We conclude that through the look come into play different aspects of youth individuality that educators should take into account when acting on sociodynamics of conflicts in schools.
\end{abstract}

Key Words: Young people, Face, Subjetivity, Body, School, Meaning

Universidad de Buenos Aires, Docente de la Facultad de Filosofía y Letras y de la Facultad de Ciencias Sociales e Investigador del Consejo Nacional de Investigaciones Científicas y Técnicas, pablodinapoli@filo.uba.ar 


\section{Introducción}

La cuestión de la mirada ha sido ampliamente abordada desde la filosofía y las ciencias sociales como una de las dimensiones centrales de la constitución identitaria y subjetiva. A través de ella (re) conocemos al otro pero también somos reconocidos y nos conocemos a nosotros mismos. Es tal vez por ello, que los sentidos y usos de la mirada se tornan altamente sensibles para los individuos, en especial para aquellos que transitan su juventud.

En el presente artículo nos preguntamos por el sentido social y subjetivo que las y los jóvenes le otorgan a sus miradas, especialmente a un tipo particular de mirada que parece constituir un eje constante de conflicto al interior del ámbito escolar. Diversas investigaciones realizadas a lo largo de nuestro continente destacan que existe una forma de mirar, denominada por las y los estudiantes como "mirar mal", la cual constituye una de las causas y manifestaciones cotidianas de conflicto y violencia en las escuelas. (Abramovay, 2006; Di Leo, 2009; di Napoli, 2014; García \& Madriaza, 2005; Kaplan, 2012; Mejía Hernández, 2013). Cabe aclarar que ese "modo" de mirar, del cual se busca dar cuenta en este trabajo, no es exclusivo del espacio escolar, sino que está presente en otros ámbitos de sociabilidad juveniles (Ness, 2004, Cerbino, 2006). El propio Goffman (1979), ya hacía referencia a este tipo de mirada como una modalidad infractora frecuente en las pandillas juveniles estadounidenses.

En la primera parte del escrito se recuperan los aportes teóricos del campo sociológico en torno al rostro y la mirada desde una perspectiva relacional ${ }^{1}$. En la segunda parte se propone un análisis de los sentidos y significados que los jóvenes le atribuyen al "mirar mal" y qué tipo de prácticas se ligan a ella en el ámbito escolar.

El material empírico que se presenta es parte de mi tesis doctoral cuyo objetivo fue comprender, mediante una estrategia metodológica cualitativa, las percepciones de violencia en el ámbito escolar de las y los jóvenes estudiantes ${ }^{2}$. El trabajo de campo se realizó en dos escuelas secundarias (medias) de gestión estatal del partido de Avellaneda, provincia de Buenos Aires, Argentina. Durante el año 2012 se llevaron a cabo entrevistas en profundidad con estudiantes de $3^{\text {er }}, 4^{\text {to }}$ y $5^{\text {to }}$ año ${ }^{3}$ (sus edades iban desde los 14 a los 18 años). La guía de entrevistas constaba de cinco ejes temáticos para conversar. Éstos constituían pautas de exploración abiertas a la posibilidad de abordar aspectos emergentes (Valles, 2002). En este artículo se hace énfasis en los conflictos que los estudiantes experimentaban con otros jóvenes. En total se entrevistaron individualmente 60 estudiantes: 26 en la escuela A y 34 en la escuela $\mathrm{B}^{4}$. La muestra estaba compuesta por 34 mujeres y 26 hombres. Los estudiantes y las estudiantes que se entrevistaron de la escuela A eran mayoritariamente de sectores populares, algunos de los cuales vivían en asentamientos urbanos precarios de la zona. En el caso de la escuela B, el alumnado con quien se dialogó era mayormente de sectores socioeconómicos medios.

Para el análisis de los datos se siguieron los lineamientos del análisis temático, el cual supone el reconocimiento de patrones dentro de los datos donde los temas emergentes devienen en categorías analíticas. Utilizando como soporte informático el programa Atlas.ti 7 se realizó una codificación por

1 Cabe advertir que en este trabajo no nos adentraremos en los desarrollos referidos a la mirada normalizadora (Foucault) ni en la perspectiva psicoanalítica de la mirada (Lacan).

2 La tesis fue realizada en el marco del programa de investigación sobre "Transformaciones Sociales, Subjetividad y Procesos Educativos" con sede en el Instituto de Investigaciones en Ciencias de la Educación (IICE) de la Universidad de Buenos Aires. La investigación fue financiada por una beca del CONICET.

3 Bajo los lineamientos de la Ley de Educación Nacional ( $\mathrm{N}^{\circ}$ 26.206) sancionada en el año 2006, la provincia de Buenos Aires opto por el establecimiento de un nivel secundario de 6 años (Ley Provincial de Educación N 13.688).

4 Con los fines de mantener el anonimato y preservar la confidencialidad de los entrevistados y de las entrevistadas se modificaron sus nombres. En cada testimonio que se cita se especifica el nombre de fantasía, el año cursado y la escuela de pertenencia. 
medio de un procedimiento mixto complementariamente inductivo-deductivo delimitando núcleos temáticos y categorías con mayor contenido inferencial.

\section{La significación sociológica de la mirada}

La relevancia sociológica de la mirada se asienta en un doble aspecto que, como da cuenta Simmel $(2011,2014)$, adquiere preponderancia en la Modernidad. Por un lado, el sociólogo alemán cataloga a la vista, junto con el oído, como uno de los sentidos superiores del individuo moderno sobre el cual descansan determinados sentimientos y formas de socialización. Si bien reconoce que los distintos sentidos operan en conjunto de forma complementaria, considera que se puede establecer cierta división del trabajo a partir de la cual diferenciar las formas de relacionarse de los individuos según se basen predominantemente en uno u otro sentido.

Por otro lado, el ojo, órgano sensorial por el cual funciona la vista, constituyen uno de los elementos centrales del rostro, parte del cuerpo del cual emerge la mirada y, como se verá, destino principal de la mirada del otro. El rostro, sector del cuerpo que queda sin cubrir, todavía desnudo, se convierte en el símbolo de la individualidad moderna, del espíritu en tanto personalidad singular.

Dice Simmel (2014), los sentidos "penetran en el sujeto en la forma de sentimiento y estado de ánimo, pero conducen hacia el objeto en la forma de conocimiento" (p. 622). La mirada es una de las dimensiones centrales en la relación epistemológica sujeto/objeto y de la constitución de la subjetividad, es decir, de la relación entre el yo y el otro. Es a través de la mirada que el sujeto busca conocer al otroobjeto, al mismo tiempo que se entrega como objeto de conocimiento del otro-sujeto. La interacción cara a cara, que no deja de ser confrontativa y conflictiva, supone para el sociólogo berlinés el momento de "reciprocidad más perfecto que existe en todo el campo de las relaciones humanas" (Simmel, 2014, p. 623), por cuanto la mirada no puede tomar nada sin dar nada a cambio.

Desde el enfoque existencialista de Sartre la cuestión de la mirada es un tanto más trágica. La mirada del otro es lo que nos da nuestro ser y a la vez nos lo quita, nos cosifica.

Si el prójimo-objeto se define en conexión con el mundo como el objeto que ve lo que yo veo, mi conexión fundamental con el prójimo-sujeto ha de poder reducirse a mi posibilidad permanente de ser visto por el prójimo. En la revelación y por la revelación de mi ser-objeto para otro debo poder captar la presencia de su ser-sujeto (Sartre, 2004, p. 284).

Al ser-visto-por-otro experimento la presencia de otra subjetividad, otra conciencia de la cual me vuelvo su objeto. La mirada ajena me otorga un en-sí, en cuanto objeto, que desconozco y que nunca podré asir dado que soy un ser-para-sí con conciencia. Sartre (2004) dirá que mi cuerpo se vuelve para-otro.

Ahora bien, es esa mirada del otro como sujeto ajeno la que nos permite tomar conciencia de nosotros mismos o de nosotras mismas. En este marco, Sartre (2004) plantea la posibilidad de mirar al otro como una forma de eludir la cosificación de nuestro ser. Echegoyen Olleta (1997) resume las dos actitudes que desarrolla Sartre frente a la mirada del otro:

o bien nos afirmamos como sujetos y en esa afirmación nos apropiamos de la libertad del otro y cosificamos su ser, o bien intentamos captar al otro en su libertad, en su ser sujeto, pero a costa de perder nuestra libertad y convertirnos en simples objetos. (...) De cualquiera de las dos maneras la relación intersubjetiva será siempre conflictiva, será una lucha entre libertades (par. 6).

Para Sartre (2004) la mirada del otro se vive como una intromisión que promueve sentimientos de miedo, vergüenza y orgullo: miedo de estar en peligro ante la libertad ajena, vergüenza de ser lo que soy frente al otro y, orgullo al afirmar mi libertad respecto del prójimo como objeto. Aquí puede hallarse una llave heurística para interpretar la relevancia que los y las jóvenes le otorgan a la mirada 
y los sentimientos que despierta en ellos y en ellas, en un momento en que están en pleno proceso de construcción identitaria.

La mirada supone un juicio de valor que "se dirige a las raíces simbólicas de un sentimiento de identidad que debe contar con el acuerdo de los otros" (Le Breton, 2010, p. 135). La mirada se inscribe en el rostro y se dirige hacia éste por antonomasia, dado que allí se plasman las configuraciones fijas de la personalidad (Simmel, 2011). El rostro, al ser cincelado socialmente a través de sus marcas, sean o no visibles, produce subjetividad (Kaplan, 2016).

El rostro es un elemento identitario del ser humano y expresa la estima social de la cual es objeto. El individuo no posee una cara en sí, sino que se constituye y reconstituye en el encuentro con el otro. El rostro no sólo se forma con los movimientos que haga el actor sino también con la mirada y los juicios que realizan los otros. Los ojos son reguladores de los rituales de interacción ya que a través de los intercambios de miradas se producen, circulan y se dejan interpretar signos que guían el desarrollo de los encuentros (Goffman, 1970).

Por su parte, Elias (1990) destaca que el rostro de una persona no sólo es una parte fundamental del cuerpo, sino que encarna la naturaleza de la identidad del yo humano:

ninguna parte del cuerpo es tan importante para la identidad del yo como la cara. Y el rostro es también lo que muestra con mayor claridad en qué medida está ligada la identidad del yo con la continuidad del desarrollo desde la infancia hasta la vejez (Elias, 1990, p. 217).

Lo singular de la sociabilidad humana, lo que nos diferencia de otros seres vivos, radica en que tenemos como principal medio de comunicación un medio que es específico de cada sociedad y no común a toda la especie y; a su vez, somos la única especie que "posee una parte del cuerpo capaz de adoptar una fisonomía tan individualizada que durante mucho tiempo, y a menudo durante toda la vida, centenares de individuos pueden reconocerse como distintos, como tales individuos" (Elias, 1990, p. 221).

Le Breton (2010) sostiene que "los movimientos del rostro participan de una simbología, son los signos de una expresividad que se muestra, que se presta a ser descifrada, aunque no sea totalmente transparente en su significación" (p. 91). Al no poder estar seguros de compartir las significaciones sobre sus rostros, los actores se saben expuestos a la ambigüedad y a los malos entendidos que pueden surgir en los procesos de descifrar o proyectar sentidos en el rostro del otro.

Si bien el carácter polisémico del rostro hace que puedan circunscribirse diferentes significados en movimientos similares, en el transcurso del encuentro cara a cara el contexto, lo que Goffman (2009) denomina frame o marco de referencia, condiciona las significaciones que los actores intercambian. Los movimientos del cuerpo no están librados al azar ni al arbitrio individual, sino que se corresponden con una organización social particular, siendo matizados tanto por los factores de la historia personal del actor, especialmente su estilo y temperamento, así como también por su posición social. Los intercambios están regulados por una simbología compartida y una negociación recíproca del sentido de los movimientos que hacen de la interacción una lucha simbólica ritualizada (Goffman, 1970).

Diferentes investigadores e investigadoras (Cerbino, 2001; Chaves, 2010; Feixa, 2006; Le Breton, 2014; Reguillo Cruz, 2000) han señalado la centralidad que tiene el cuerpo para las personas jóvenes en sus relaciones intersubjetivas. Aquí recuperamos la metáfora del cuerpo como cartografía del sujeto juvenil, es decir, como espacio de enunciación de nuevas formas de escritura, de registro de sentido y de saberes constitutivos de modos de ser y estar en el mundo (Cerbino, 2001).

En un momento vital donde se amplían los márgenes de autonomía así como también las responsabilidades individuales, para las personas jóvenes adquiere mayor relevancia normativa los vínculos con sus pares y con el grupo generacional coetáneo. 
La libertad está limitada por la mirada de los otros, el poder del grupo para inducir normas flexibles pero pregnantes. La cultura de los pares suplanta la de los padres (...). El foco de la estima de sí se desplaza hacia la mirada de los otros más cercanos, no ya los padres, cuyo amor es seguro, sino aquel, despiadado y siempre cuestionado, de los pares, cuyo juicio se enuncia según el grado de coincidencia o no con modelos circundantes y provisionales. En la adolescencia, la ropa, el peinado, las actitudes -en suma: el aspecto- son elaborados como un lenguaje, una chapa de reconocimiento. (Le Breton, 2014, p. 77)

En los jóvenes la mirada (del y hacia el otro) adquiere relevancia como una dimensión expresiva, de comunicación, así como también un eje de conflictividad y un instrumento de confrontación entre sus pares.

\section{La mirada como eje de conflicto}

A lo largo del proceso de investigación, el estudiantado relató diferentes tipos de conflictos que habían experimentado, en lo personal, o con sus amistades y compañeros o compañeras. En primera instancia, la mayoría afirma que se pueden originar por nimiedades, restándole valor a sus causas. Sin embargo, al indagar con mayor profundidad se observa que las personas jóvenes tienen en claro los motivos más resonantes por los cuales se producen conflictos.

Entre los motivos de conflicto que menciona el alumnado como frecuentes se identifican seis agrupados del siguiente modo: a) por la realización de tareas escolares, b) por rivalidades de los vecindarios de residencia, c) por rivalidades en juegos deportivos, d) por "hablar mal" de otro/a, e) por una chica o un chico ${ }^{5}$ y, f) por "mirar mal". En esta oportunidad se analiza el último de ellos, el cual parece ser uno de los más álgidos e intensos entre las personas jóvenes ${ }^{6}$. Cabe aclarar que cada uno de los motivos de conflicto que se mencionaron no son excluyentes, sino que en muchas ocasiones se producen entremezclados y se retroalimentan entre sí.

Como se mencionó más arriba, la mirada, y el rostro en general, tienen un rol preponderante en la interacción entre las personas jóvenes. La forma de mirar adquiere una multiplicidad de sentidos y constituye un mecanismo de comunicación por el cual se puede salvar una situación (Goffman, 1970), así como también quebrarla rotundamente. Aquí se indaga cómo a través de la mirada se pueden desarollar situaciones de conflicto y violencia.

\section{Los modos de "mirar mal"}

Diversas discusiones, peleas y/o situaciones de violencia narradas por las personas jóvenes tenían como preludio intercambios de miradas. Casi todo el estudiantado hizo referencia a un tipo particular que denominó como "mirar mal".

P: ¿Hubo situaciones de violencia acá en la escuela?

N: Las chicas, pero... es por algo tan boludo que... yo lo dejo pasar. Es porque "ay, me miró mal, y yo la miraba mal", se siguen mirando mal. Por una mirada, se miran mal, o sea... Es re tonto. (...) los varones es muy tonto porque dicen "pero me miró mal", como que se enojan, ya por una mirada y revolean todo.

(Noelia, 3ro. - Escuela A)

Si vos te fijaras, la mayoría de las peleas empieza con un "no, porque me miró mal”, porque qué sé yo. Entonces cuando los miran mal, se sacaron, "qué te pasa, qué me miras asî́, entonces empiezan...

(Adela, 4to. - Escuela B)

5 Refiere a conflictos derivados de noviazgos, amores no correspondidos, infidelidades y/o celos entre estudiantes.

6 Los otros motivos de conflicto han sido abordados detalladamente en di Napoli (2016). 
Abramovay (2006) fue una de las primeras investigadoras que identificó en Brasil el "mirar feo" como una forma de comunicación en la cual no intervenía la palabra ni el contacto físico, pero que podía generar conflictos entre el estudiantado y también ser percibido como violencia. Como también sostienen García y Madriaza (2005) para el caso chileno, esta mirada es parte de un código normativo juvenil de convivencia implícito de difícil comprensión para las personas adultas que habitan las escuelas. Ahora bien, dada la multiplicidad de gestos que estructuraban las miradas de las y los estudiantes en las escuelas, nos preguntábamos en qué consistía ese tipo de mirada:

\section{P: Recién nos hablaste del tema de "mirar mal". ¿Qué significa?}

D: Que pasen y te queden mirándote. Una cosa es que cuando vos te cruzas a una persona la mires, pero otra es que te miren así mal, de reojo... Y te quedan mirando hasta que no te vas y te quedan mirando y no estás lejos no te dejan de mirar

(Daniela, 4to. - Escuela B)

Una mirada fija sobre alguien, que permanece más tiempo del socialmente reglado, genera una sensación de penetración visual en el territorio del yo que incomoda o molesta, al margen de si las personas se conocen o tienen algún tipo de conflicto previo. Efectivamente, la mirada que se prolonga con o sin razón se convierte en una "mala" mirada. Mirar fijo a alguien ("que se te queden mirando") o mirarlo "de arriba abajo" son los elementos principales por los cuales los y las estudiantes describen la mecánica del "mirar mal". En el siguiente fragmento se muestra cómo una compañera le señala a la otra que una tercera persona la estaba mirando de mala manera:

\footnotetext{
Pero también yo me doy cuenta que hay mucho problema en el colegio de que ésta me mira mal, ésta me empuja. Hay una chica, que no si es de quinto o sexto, que Alejandra me dice "mira, esa me tiene la re bronca”, y yo le digo "¿Cómo se da cuenta que te tiene bronca? ¿Te lo dijo?”. Y agarra y me dice "no, mira cómo me mira” y pasa la piba y la mira de arriba abajo, ¿viste? Como mirándola toda; y yo digo “„nooo!”. Y Alejandra corte que la empuja, pero no se llegaron a pelear. Siempre, pero siempre desde que yo vine con la misma piba, pero nunca se agarran. Yo a la chica no la conozco.
}

(Melisa, 4to. - Escuela A)

Esas miradas expresan una forma de comunicación particular entre las personas jóvenes. Cuando hablamos de las miradas no sólo nos referimos a los ojos, sino al rostro completo que las expresa y acompaña. La mirada forma parte de un idioma facial (Le Breton, 2010) compartido en la interacción social de los individuos. Justamente, esta es una de las características que diferencia a los seres humanos en su individualidad, de otros seres vivos (Elias, 1990). Es decir que la sociabilidad humana se caracteriza por una forma de comunicación cuyo lenguaje se aprende, es equivoco y adquiere diversos significados según los grupos y contextos sociales en los cuales se interactúa.

Algunos estudiantes describen el "mirar mal" como una mirada con: "cara de asco", "cara de enojado", "cara de malo", "cara de desprecio" y, cuando "te fruncen la cara". Ellos ponen el acento fundamentalmente en el rostro, el cual sintetiza dicha mirada a través de diversas caras. Los calificativos (expresados en "cara de...”) aluden a un mismo sentido: la inferiorización del otro.

El "mirar mal" excede a los ojos y al rostro que la expresan e involucra al cuerpo en su totalidad. Los y las estudiantes no saben bien cómo expresar en palabras el significado de esa mirada pero la comprenden claramente a través de su experiencia corporal y emocional. Una alumna nos dice "no sé qué quiere decir, pero te rebajan (...) te das cuenta con la mirada". Se trata de lo que Bourdieu (1999) denomina conocimiento por cuerpo, es decir, que a través de la vivencia corporal esa mirada adquiere su significado.

\section{P: ¿Cómo me doy cuenta si me "miran mal”?}

L: Porque te fruncen la cara, te empiezan a mirar como enojados, ya te das cuenta... O si no te rebajan, te miran de pies a cabezas y ya está, ya te das cuenta. O si no te codean, te hacen así con el hombro... A mí me hicieron varias veces pero no les doy bola, no quiero buscar pelea.

(Lali, 4to. - Escuela A) 
Esta modalidad de mirada no se compone únicamente de movimientos oculares, sino también de otros gestos corporales como "pasar y que te codeen", "pasar, mirar y decir algo por lo bajo", "mirarte y hablar con otro riéndose o señalándote". Estas son algunas de las tantas combinaciones por las cuales la mirada se vuelve más ofensiva y motivo de conflicto.

Una característica a destacar de este tipo de mirada es que, la mayoría de las veces, no se produce estrictamente en un encuentro cara a cara, sino más bien en situaciones de tránsito o distantes: al ir caminando, al cruzarse al pasar o al estar hablando entre amigos y que desde el otro lado del patio alguien esté “mirando mal". Se trata de un diálogo no frontal donde la palabra está ausente y el cuerpo comunica. Una entrevistada nos contaba: "no le decís nada, pero con la mirada le decís todo ¿entendés?”.

\section{Una mirada inferiorizante}

Existe un fuerte consenso entre el alumnado sobre que "mirar mal" constituye una forma de "rebajar" al otro. Al mirar de arriba abajo se busca interpelar al otro a través del menosprecio. Se trata de una mirada que porta un sentido simbólico de desprecio social y que es percibida como una práctica inferiorizante.

\section{P: Recién dijiste algo del "mirar mal" ¿Qué es eso?}

A: Como que te sobran, no sé cómo te puedo explicar. Como que vos sos menos cosas que él, sentís eso. (Adriana, 5to. - Escuela B)

M: Para mí es cuando te miran con desprecio: "te voy a mirar mal asî" qué sé yo. También para que tengas respeto o que te pueda decir "te voy a mirar mal para que vos te quedes chico", una forma de decir y el otro quede más "grande". He visto también en los recreos gente que ha pasado y te mire mal a vos. A mí me han mirado mal un montón de chicas.

(Macarena, 4to. - Escuela B)

En esa mirada se juega el reconocimiento de los protagonistas como iguales. Según Le Breton (2010) "la cara o el rostro valen por el hombre completo, por el sentimiento de identidad que lo caracteriza y por la estima de la cual goza de parte de los otros" (p. 124). A través del rostro se puede leer la dignidad social de la que un actor es objeto. El propio rostro se constituye a partir de la mirada de los otros, lo que significa que los otros son el espejo en el cual "el actor percibe una imagen satisfactoria de sí, se reconoce en él" (Le Breton, 2010, p. 126). Por eso, la mirada puede penetrar en lo más hondo de la subjetividad. El que "mira mal" intenta rebajar al otro, hacer que se sienta "nada" o "chico", es decir, negarlo como un igual. Le Breton (2010) sostiene que

\footnotetext{
la mirada, socialmente habilitada para conferir una legitimidad, para garantizar la existencia, también lo está para refutarla, negarla o suspenderla. El tono de los intercambios oculares no siempre es feliz. La mímica de desaprobación o de desprecio, manera ritual de romper la etiqueta de discreción, señala el intento, más o menos exitoso según la situación, de intimidar al otro, de reprobar su apariencia o conducta (p. 135).
}

El "mirar mal" implica un trabajo de la cara que tiene una función más bien disruptiva que equilibradora de la situación. En términos de Goffman (1970), la persona que "mira mal" busca mantener su cara a costa de que el otro pierda la suya. Perder la cara supone un detrimento del prestigio frente a los otros dando lugar a sentimientos de vergüenza o humillación ligados a su condición inferiorizada.

Este tipo de mirada es experimentada como un avasallamiento a su identidad personal y/o grupal. Con esta mirada se puede "tocar" a alguien a la distancia. Di Leo (2009), siguiendo a Sartre, señala que esta mirada refuerza 
la objetualización del sí mismo, propia de todo encuentro intersubjetivo, disolviendo su autoconfianza existencial y negando su condición de sujeto. Por ende, la reacción del yo frente a la percepción de esta forma de desprecio, la expresión de su lucha por el reconocimiento, adquiere, en general, una intensidad afectiva directamente proporcional al grado de degradación existencial experimentada (p. 208).

El sentimiento existencial de los y las estudiantes puede ser una de las causas por las cuales este tipo de miradas constituye uno de los focos de conflicto más álgido que los lleva en muchos casos hacia la confrontación física. Lo que está en juego es la existencia simbólico-subjetiva y el reconocimiento social en un momento en que las personas jóvenes están en plena construcción identitaria. Ser mirado o mirada "es captarse como objeto desconocido de apreciaciones incognoscibles, en particular, de apreciaciones de valor" (Sartre, 2004, p. 294). Quien "mira mal”, le adjudica al otro una menor valía social de su ser al mismo tiempo que lo objetualiza negándolo como sujeto. Esto genera una doble amenaza respecto de su conciencia de sí mismo y de su reconocimiento como sujeto frente a otros.

\section{La mirada sobre el aspecto estético}

Muchas veces, el locus de esta mirada se posiciona sobre la apariencia de las personas jóvenes. La ropa que utilizan expresa un modo de diferenciación (ya sea de distinción o de estigmatización) cuyos sentidos están en plena disputa. Particularmente entre las estudiantes mujeres, la forma de vestirse podía ser un epicentro de conflicto atravesado por las miradas.

\footnotetext{
P: Vos justo decís "trato de no mirar a nadie”. ¿Qué significa esto de mirar?

G: Y por ejemplo, pasa una villera ${ }^{7}$ y vos estás bien vestida, o no sé, tenés un jean lindo, qué sé yo... o, no te digo que yo sea linda pero, por ejemplo sos linda y te miran mal, te miran de arriba abajo y te miran con cara, así... [Hace el gesto]. A mi hermana en la escuela le pasó (...)

(Griselda, 5to. - Escuela B)
}

Kaplan (2013) sostiene que, "las marcas del cuerpo funcionan como metáforas sociales que simbolizan o cristalizan los procesos de inclusión y exclusión" (p. 51). No se trata de una cuestión referida solamente a una diferencia de gustos, sino que esos gustos son el resultado de un entramado sociocultural desigual en el cual se plasma una matriz de clasificación social. Siguiendo a Le Breton (2014) hoy la apariencia corporal es el lugar privilegiado de la estima de sí y del sentimiento de identidad de las personas jóvenes. El mercado de consumo les provee de signos identitarios para ser reconocidos como parte de un grupo o diferenciarse entre sí. Ahora bien, ese sentimiento de identidad siempre está amenazado por la mirada de otros jóvenes.

La imagen es la vía del reconocimiento si es validada por los pares. No se trata ya de ser uno por lo que hace sino por lo que exhibe. El joven experimenta la sensación de estar siempre bajo la mirada de los otros, de ser objeto de su atención meticulosa, de sus alabanzas o de su reprobación. (Le Breton, 2014, p. 81)

Diferentes investigaciones (Abramovay, 2006; Kaplan, 2012, Blázquez, 2010) han señalado que la desigualdad social expresada en la falta o la ostentación por parte del otro genera un sentimientos de inferioridad que las y los jóvenes buscan revertir a partir de la mirada.

Con la mirada se le comunica al otro que "le tiene bronca o envidia", por ejemplo por la forma de vestirse. Esas emociones de bronca o envidia podrían estar expresando conflictos a partir de formas de identificación fallidas (Cerbino, 2006).

$7 \quad$ El término originalmente refiere a los individuos que residen en asentamientos urbanos precarios y socialmente vulnerables. Sin embargo, muchas veces se utiliza para referirse de forma despreciativa hacia las personas. 


\section{Mirar para "buscar pelea"}

El menosprecio hacia el otro que expresa esa mirada es interpretado como una provocación. Lo que se busca es conflictuar con alguien. Por ello, los y las estudiantes interpretan el "mirar mal" como una "seña" para pelear o una forma de "buscar pelea".

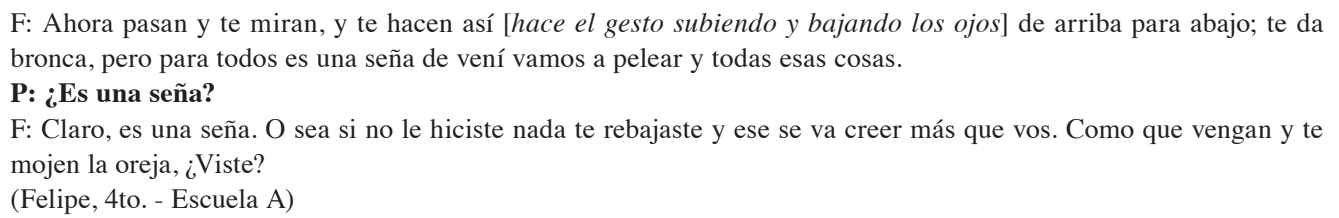

Siguiendo los testimonios se puede observar que hay muchas circunstancias o ninguna en particular por la cual se pueden empezar a "mirar mal". Conflictos o rivalidades pasadas, "broncas" personales que están latentes o, sentimientos de envidia sobre el otro, son algunos de los argumentos que nos transmiten los estudiantes. Ante la falta de un hecho concreto para la confrontación explicita, esta forma de mirar opera como catalizador de conflictos previos o tensiones latentes entre compañeros. Según Cerbino (2006) los actos de violencia se producen, en parte, "por la imposibilidad de construir una mediación simbólica: la posibilidad de apalabrar esa mirada, de encasillarla o asignarle un sentido soportable o conveniente" (p. 39).

"Mirar mal" no sólo es una provocación para que el otro reaccione o una "seña" para pelear, sino también una "excusa para pelear" dado que se acusa al otro con el que se quiere confrontar de que aquel está "mirando mal". Karen (3ro. D - Escuela A) nos cuenta sobre un grupo de amigas que, cuando le tienen bronca a alguna compañera van a buscarla para observarla y esperar que la "miren mal o algo". Si bien en esta investigación este sentido y práctica de "mirar mal" se observa por igual entre hombres y mujeres, Mejía Hernández (2013), quien analizó las relaciones de violencia en escuelas de México según el género de los estudiantes, identificó que las "miradas de barrida" para retar a una rival eran propias de la conflictividad entre las jóvenes.

\section{Tácticas frente al "mirar mal"}

Goffman (1970) sostiene que

\footnotetext{
la línea mantenida por y para una persona durante el contacto con otras tiende a ser de un tipo institucionalizado legítimo (...) Dados sus atributos y la naturaleza convencionalizada del encuentro, tendrá ante sí una muy escasa elección de líneas y le esperará una muy pequeña elección de caras. (pp. 14-15)
}

Si bien el autor se refiere en este pasaje a situaciones cotidianas donde se busca salvar la situación permite abordar las reacciones posibles de las personas jóvenes frente al "mirar mal". Las dinámicas que adquiere la mirada en la sociabilidad juvenil no pueden ser abordadas sin considerar las formas de jerarquización que se buscan (re)producir, así como sus impugnaciones y sus intentos de sostener un principio de igualdad entre los sujetos.

Entre los y las estudiantes podemos observar diferentes formas de afrontar las situaciones conflictivas o desafiantes que se les presentan. Esto no significa que todos se rijan por la misma modalidad o, que quienes dicen actuar de una forma lo hagan siempre de ese modo. El tipo de conflicto, el contexto en el cual se produce y entre quienes se presenta, condiciona la forma de interactuar. En este apartado nos proponemos indagar sobre el repertorio de prácticas que los y las jóvenes ponen en juego y/o de las cuales disponen para utilizar. Nos servimos de la noción de táctica desarrollada por De Certeau (2000) como una 
acción calculada que determina la ausencia de un lugar propio. Por tanto ninguna delimitación de la exterioridad le proporciona una condición de autonomía. La táctica no tiene más lugar que el del otro. Además, debe actuar con el terreno que le impone y organiza la ley de una fuerza extraña (p. 43).

Las distintas formas de proceder del estudiantado las hemos agrupado en las siguientes categorías empezando por las de menor confrontación hasta aquellas que llegan al uso de la fuerza física: a) tácticas de evitación, b) tácticas de resistencia y, c) tácticas de confrontación. (Figura 1)

Figura 1

Tácticas frente al "mirar mal"

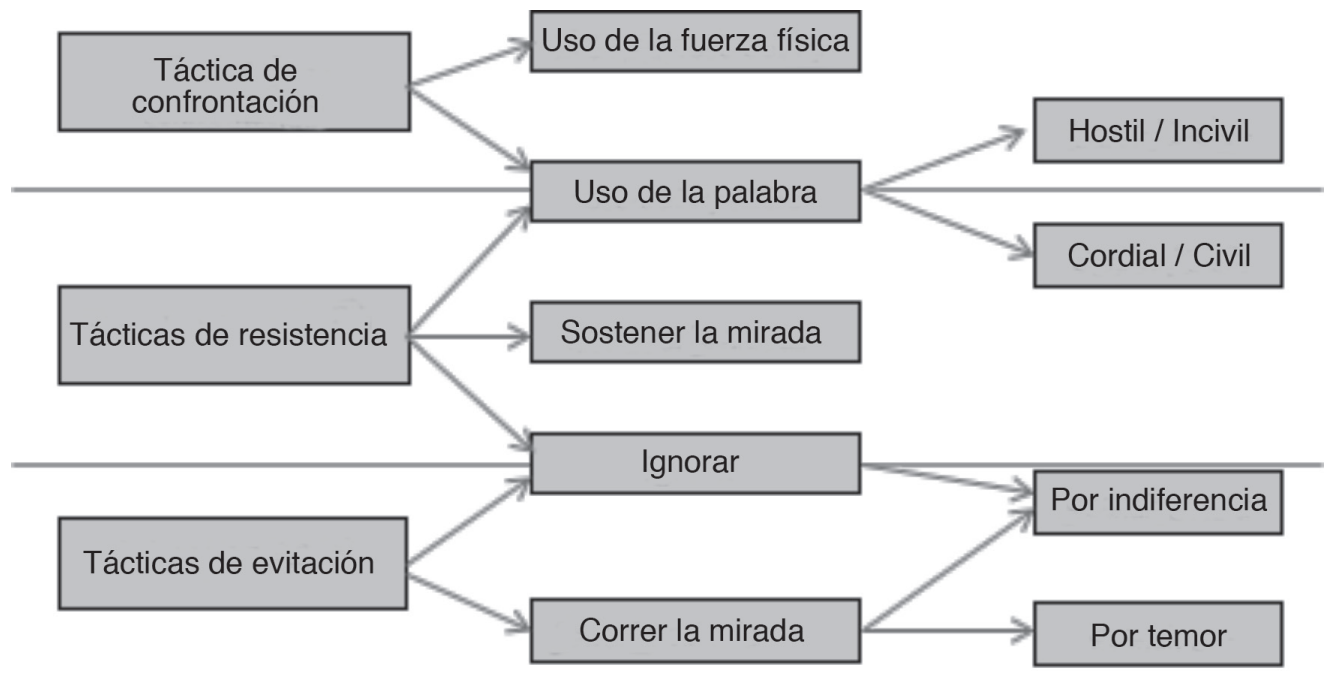

Fuente: Elaboración propia.

\section{Tácticas de evitación: entre el temor y la indiferencia}

Una de las tácticas desplegadas por los estudiantes parece ser la de evitar el contacto con la mirada de los otros, especialmente con las personas jóvenes que son tipificadas como que "buscan pelea". Esta práctica, en algunos casos, puede dar cuenta de una falta de aplomo (Goffman 1970) desde los esquemas prácticos de acción del sujeto, ya que esa mirada es reconocida por el propio estudiantado como una práctica que menosprecia.

Hay que mirar para otro lado y decir listo.

(Dana, 5to. - Escuela B)

"Correr la mirada" o "mirar para otro lado" son algunas de las tácticas utilizadas por el estudiantado para no confrontar. En esta práctica no confrontativa observamos dos sentimientos distintos: miedo e indiferencia.

A: Es como que pasan y al reconocerte, te miran mal, entonces vos mirás con cara de orto, y cuando pasa un tiempo, o sea, un espacio, “¿qué carajo me mira? ¿Qué le pasa a esa?” Entonces empiezan (...)

P: Si a vos te miran mal, ¿qué haces?

A: Nada, porque, o sea... Por más que me de bronca, por más que me den ganas de saltarle y decirle "¿Qué te pasa? ¿Por qué me mirás así?” ¡No puedo hacer nada! Porque voy a lograr venir a mi casa con un ojo así hinchado con 
medio pelo menos, y es al pedo. Aparte no da ensuciarte, porque es como quedás "ah, sí, ésta se cagó a piñas, porque se revolcó por el piso por una pelotudez".

(Adriana, 5to. - Escuela B)

\section{P: ¿Te ha pasado que a vos te miran mal?}

K: Sí, pasa a veces, pero... la persona se cansa... hubo una par de persona', ponele, con A, que se cansó de mirarme mal porque yo ni bola le pasaba. Y me decían “¿Por qué no le decís algo a A que te mira mal, te mira para el orto?”. Y le digo "si tiene un problema, supongo, ella tanto que se hace la que... la que caga a palo' a todo', la que se re para, yo supongo que si tiene un problema me lo va a decir, conociéndola como es, me lo va a decir. Y si no tiene ninguno, bueno, que se canse de mirar mal porque yo no le voy a dar bola". Mirá si voy a dejar que... la... directora me... porque si te agarrás con alguien, el problema es de las dos, a las dos le' hacen un acta. Yo no voy a dejar que me hagan un acta o algo por culpa ellas.

(Karen, 3ro. - Escuela A)

Aquí podemos observar cómo operan los mecanismos de autodominio por los cuales algunos y algunas estudiantes logran regular sus comportamientos aunque la situación les cause "bronca". Retomando los postulados de Elias (1990), en el caso de Adriana se entrecruzan tanto coacciones externas con autocoacciones. Ella se contiene, por un lado, por el peligro que implica la amenaza física externa del otro y, por el otro, por temor a la pérdida de prestigio que implicaría que sus compañeros y compañeras se enterasen de que "se revolcó por una pelotudez". En cambio, estudiantes como Karen prefieren evitar la confrontación, no por el temor a la agresión física sino por la sanción normalizadora que les pueden aplicar en la escuela. Podríamos decir que en ambos casos hay un cierto temor, respecto a las consecuencias que puede traer un posible enfrentamiento, pero de diferente cariz. En el primer caso se trata de un sometimiento al otro en cuanto par (o al qué dirán de los otros jóvenes), en el segundo caso consiste en un acatamiento a las normas institucionales de la escuela. Frente a su compañera que la mira mal, Karen expresa absoluta indiferencia en igualdad de posición.

La táctica de la indiferencia, entendida como un mecanismo de autodefensa, implica un trabajo sumamente complejo sobre uno mismo. En este punto vale realizar una distinción. En algunos casos la indiferencia parece no sólo ser una respuesta tácticamente elaborada, sino antes bien una práctica hecha cuerpo. Aquí seguimos la perspectiva de Hochschild (2008) sobre la articulación entre las reglas de sentir y las reglas de expresión: lo que el sujeto expresa en esa indiferencia es lo que experimenta emocionalmente en su propio cuerpo, literalmente la mirada del otro no "lo toca".

I: Igual a mí no me molesta, me da igual.

P: ¿Qué haces cuando te "miran mal"?

I: No nada, lo ignoro.

(Ignacio, 5to. - Escuela B)

P: ¿Cuánto te "miraron mal”, vos que hiciste?

L: nada me di vuelta y seguí caminando, como que no le di importancia, pero si me molesto, para que decir algo, porque capaz que la mirada es así de ella, entonces seguí caminando y no le di importancia.

(Laura, 4to. - Escuela A)

Para ciertos estudiantes esta indiferencia implica antes un manejo más efectivo sobre las formas de expresión que sobre las maneras de sentir: el sujeto actúa ignorando al otro, aunque en su cuerpo percibe la mirada del otro y esta lo moviliza emocionalmente, le molesta, le da "bronca".

\section{Tácticas de resistencia: sostener la mirada}

En algunos casos los y las estudiantes utilizan la indiferencia como una táctica de resistencia para negar la presencia del otro, una suerte de desprecio que, saben, no suprime la tensión sino que le da continuidad. Sin embargo, para algunos y algunas estudiantes la práctica de "ignorar" tiene sus límites. 
Si un compañero o compañera persiste con la misma forma de mirar durante un tiempo o aumenta la provocación, se torna insostenible la evitación y se debe hacer frente de algún modo.

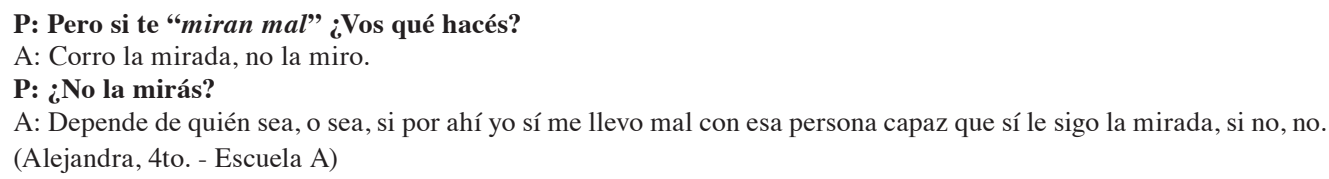

Sostener la mirada es una de las tácticas con las cuales las personas jóvenes intentan resistir simbólicamente la lógica de inferiorización que trae aparejado el mirar mal. En esta instancia, las miradas se cruzan en un pie de igualdad sin que ninguno logre la subordinación del otro, al menos antes de pasar al plano del uso de la palabra o la agresión física.

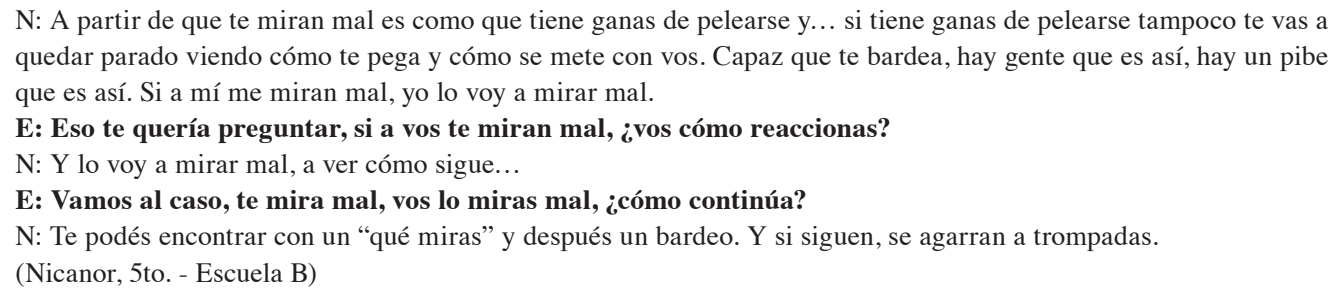

Sostener la mirada es una forma de equiparar las posiciones y quedar a la expectativa de lo que haga el otro. Constituye una primera prueba hacia el otro. Como se observa en los testimonios de los y las estudiantes, es posible que el cruce de miradas se prolongue hasta que uno de los protagonistas salga de escena o que, luego de un tiempo, la tensión de esas miradas desemboque en una interpelación verbal o física. El equilibrio de poder se torna así sumamente inestable.

El empleo de la palabra en su forma interrogativa es otra de las respuestas posibles frente a las miradas. Teniendo en cuenta la entonación y gesticulación su uso supone dos tácticas diferentes: a) el uso cordial/civil y, b) el uso hostil/incivil que lleva a la confrontación.

El uso cordial de la palabra busca esclarecer la situación y destrabar la tensión. Se podría decir que este tipo de respuesta todavía opera como una táctica de resistencia, dado que la interpelación se realiza desde un posicionamiento de simétrica frente al otro.

\begin{abstract}
P: ¿Qué haces si a vos te "miran mal"?
V: Nada, no lo miro, directamente sigo en la mía. A veces me sorprendo, ¿no? Porque a mí no me ha pasado mucho. A veces cuando veo a alguien que no lo conozco y que me mira mal me sorprendo, ¿entendés? Como que lo miro con una cara de estar sorprendido de por qué me mira mal. A veces me pregunto por dentro por qué me mira mal. A veces lo que le diría es por qué me mira mal, pero no para quilombo si no para saber... esa persona que no la conozco me mira mal, sin saber quién es ni un por qué. Pero creo que a otra gente si le influye como para ya tener problemas. Capaz que a una persona la miras mal y se siente tan zarpada que te dice “¿qué te pasa que me mirás mal?" y ya se arma problema. (Vicente, 5to. - Escuela A)
\end{abstract}

\title{
Tácticas de confrontación: del “¿qué mirás?” al uso de la fuerza física
}

El uso hostil de la palabra lo enmarcamos dentro de las tácticas de confrontación en cuanto es una práctica que busca aumentar el nivel de enfrentamiento desafiando al alter que mira.

Sentís que te están mirando mal. Capaz un pibe con el que no tenés trato y se te queda mirando fijo, vos le decís “QQué mirás? ¿Algún problema?” Te me quedás mirando y te digo "¿Pasa algo? ¿Te debo algo? ¿Necesitas algo?" Capaz otros reaccionan de otra manera. No sé, yo te lo digo mal, de mala manera, porque es así porque es así. (...) Y 
depende de lo que vos me digas ahí yo hago algo. Si me respondes mal, vamos a ver qué pasa; si me decís "no nada", listo, nada, no me mirés más y listo. Si se te queda mirando fijo por algo es.

(Gabriel, 4to. - Escuela A)

La respuesta verbal hostil lleva en mayor medida a la escalada del conflicto, ya sea en términos verbales o mediante la confrontación física. Cabe destacar que en algunas ocasiones el uso hostil de la palabra por parte del sujeto destinatario de la mirada logra subvertir la jerarquía cuando la persona que lo miró no aumenta la apuesta. Esta situación se da fundamentalmente cuando aquel que busca un conflicto arguye que alguien lo miró mal y lo interpela diciendo “qqué mirás?”. En ese caso quienes no quieren confrontar intentan abandonar la situación lo más rápido posible.

En ciertas configuraciones sociales, el uso y la destreza de la fuerza física ocupan los niveles superiores en la escala de valores, desplazando o subordinando a otras estrategias más pacíficas de trato, como la discusión, el debate, la persuasión o el convencimiento. Ness (2004), en su investigación con jóvenes mujeres de sectores populares que vivían en la ciudad de Filadelfia, sostiene que para ellas la agresión social (de tipo más simbólica) no actúa como un sustituto de la agresión física.

Si bien en ambas escuelas existían situaciones de violencia física entre estudiantes, en la escuela A fue en donde nos relataron más episodios. Asimismo, en esa escuela fue en la cual varios alumnos no consideraban el uso de la fuerza física como una forma de violencia salvo que esté en juego la propia vida (di Napoli, 2016).

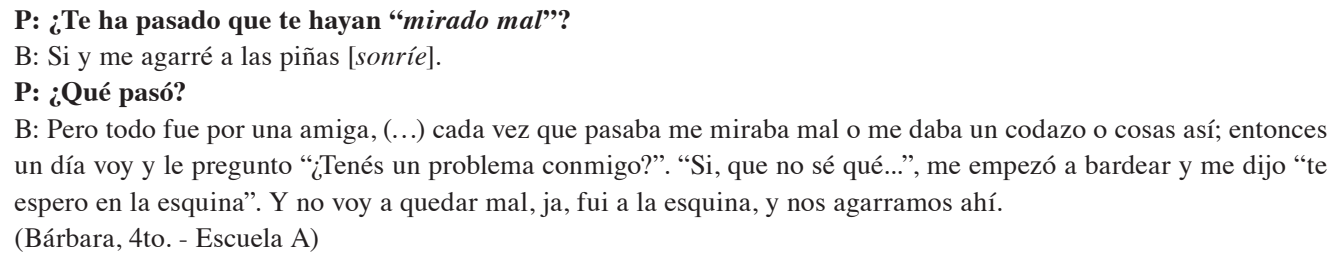

La violencia física se presenta como un medio plausible de ser utilizado para dirimir diversos conflictos entre las personas jóvenes. El uso de la fuerza física es percibido por varios y varias estudiantes como una obligación para, por un lado, no quedar como cobardes y, por otro lado, demostrar coraje. Este tipo de reacciones, generalmente asociado al género masculino, también existe entre las mujeres.

Por último, es importante destacar una cuestión central del proceso de interacción de la mirada. Las respuestas tácticas varían según el conocimiento del otro, la posibilidad de prever su acción y la predisposición a usar la fuerza física. Es decir que la respuesta es siempre situada en función del espacio, el sujeto y la correlación de fuerzas.

\section{Conclusiones}

A lo largo de este artículo se buscó analizar los usos del sentido de la vista a partir de un tipo particular de mirada a la que las personas jóvenes le otorgan una alta relevancia simbólico-subjetiva. El "mirar mal" atraviesa la sociabilidad del estudiantado en el espacio escolar y trae aparejado una serie de conflictos y emociones. A través de la mirada se ponen en juego diferentes aristas de la individualidad: el reconocimiento como persona, la pertenencia a un determinado grupo y la construcción subjetiva de una identidad propia.

El cuerpo no sólo es un soporte para ver o ser visto, sino también es el foco donde se posan las miradas para (re)(des)conocer social e individualmente al otro. La mirada de los otros sobre las marcas corporales suelen ser parte importante de las pruebas a resolver con el objeto de ser parte de un grupo o de quedar excluido o subordinado de éste. 
Las miradas siempre son arena de conflicto porque en ellas se juega la subjetividad profunda. En el caso de "mirar mal" se trata de una práctica que busca explícitamente el desconocimiento del otro como un igual. Se podría decir que al "mirar mal" el individuo inferioriza al otro rompiendo simbólicamente su cara. Si la otra persona responde, puede ser que lo haga en el mismo plano simbólico o que directamente intente "romperle la cara" 8 pero ya físicamente. Se trata de dos niveles de quiebre del rostro: uno invisibilizado ante los ojos de los demás y otro explicitado en situaciones que son tipificadas como "violentas" por los actores de la institución escolar. La dinámica conflictiva en torno a las miradas (que puede ser latente y anterior a la propia situación de "mirarse mal") tiene la particularidad de incrementarse por un lado, porque opera como un gesto continuamente abierto a la interpretación y, por el otro, porque busca resolverse a partir de la fuerza (física o simbólica), la cual puede conducir a una escalada de violencia.

Los usos y sentidos que despliegan los estudiantes alrededor de la práctica de "mirar mal" posicionan a esa mirada como una forma particular de uso de la fuerza que permite reconstruir cierta jerarquía y establecer distinciones entre sujetos que desde las autoridades escolares son considerados como pares. Sin embargo, la jerarquización a través de esta forma de mirar se encuentra débilmente estructurada, ya que las normas sociales que regulan estas relaciones intersubjetivas escapan a la regulación explícita de la institución escolar y se enmarcan en pautas muchas veces tácitas. El estudiantado se resiste no sólo a las formas de socialización escolar que lo interpela como pares iguales, sino también a las formas de sociabilidad que lo inferioriza y no le concede una reciprocidad que otorgue reconocimiento a sus particularidades identitarias. Conocer y comprender por parte de los agentes educativos estas sociodinámicas juveniles resulta relevante para la construcción de dispositivos escolares para la resolución pacífica de los conflictos.

\section{Referencias}

Abramovay, Miriam. (2006). Cotidiano das escolas: entre violências. Brasília: UNESCO-SECAD. di Napoli, Pablo. (2014). Entre el conflicto y la violencia en la escuela. En J. A. Castorina \& V. Orce, Perspectivas en la investigación educativa: contribuciones de los/las investigadores/as en formación (pp. 127-146). Buenos Aires: Editorial de la Facultad de Filosofía y Letras (UBA).

di Napoli, Pablo. (2016, noviembre). Sociodinámica de los conflictos entre estudiantes de educación secundaria. Ponencia presentada en la V Reunión Nacional de Investigadores/as en Juventudes Argentinas, "Juventudes en disputa: permeabilidades y tensiones entre investigaciones y políticas". Córdoba, Argentina.

Blázquez, Gustavo. (2010). De cara a la violencia. Agresiones físicas y formas de clasificación social entre mujeres jóvenes de sectores populares en Argentina. Sexualidad, Salud y Sociedad. Revista Latinoamericana, 10, 10-40.

Cerbino, Mauro. (2001). Para una antropología del cuerpo juvenil. En C. Chiriboga, C. Tutivén, \& Cerbino, Culturas juveniles: cuerpo, musica, sociabilidad \& género (pp. 57-66). Quito: Abya-Yala.

Cerbino, Mauro. (2006). Jóvenes en la calle: cultura y conflicto. Barcelona: Anthropos Editorial.

Chaves, Mariana. (2010). Jóvenes, territorios y complicidades. Una antropología de la juventud urbana. Buenos Aires: Espacio Editorial.

De Certeau, Michael. (2000). La invención de lo cotidiano. México: Universidad Iberoamericana.

Di Leo, Pablo (2009). Subjetivación, violencias y climas sociales escolares. Un análisis de sus vinculaciones con experiencias de promoción de la salud en escuelas medias públicas de la Ciudad Autónoma de Buenos Aires (Tesis doctoral). Universidad de Buenos Aires, Buenos Aires, Argentina.

8 Modismo que en Argentina suele usarse de forma frecuente como amenaza o insulto. 
Echegoyen Olleta, Javier. (1997). Historia de la Filosofía: Vocabulario y ejercicios. Volumen 3: Filosofía Contemporánea. Madrid: Edinumen.

Elias, Norbert. (1990). Cambios en el equilibrio entre el yo y el nosotros. En La sociedad de los individuos (pp. 177-270). Barcelona: Península.

Feixa, Carles. (2006). Generación XX. Teorías sobre la juventud en la era contemporánea. Revista Latinoamericana de Ciencias Sociales, Niñez y Juventud, 4(2), 21-45.

García, Mauricio \& Madriaza, Pablo. (2005). Sentido y Sinsentido de la Violencia Escolar: Análisis Cualitativo del Discurso de Estudiantes Chilenos. Psykhe, 14(1), 165-180.

Goffman, Erving. (1970). Sobre el trabajo de la cara. Análisis de los elementos rituales de la interacción social. En Ritual de interacción (pp. 13-47). Buenos Aires: Tiempo Contemporáneo.

Goffman, Erving. (1979). Los territorios del yo. En Relaciones en público: microestudios del orden público (pp. 46-77). Madrid: Alianza.

Goffman, Erving. (2009). La presentación de la persona en la vida cotidiana. Buenos Aires: Amorrortu.

Hochschild, Arlie. (2008). La mercantilización de la vida íntima apuntes de la casa y el trabajo. Buenos Aires: Katz.

Kaplan, Carina. (2012). Mirada social, exclusión simbólica y auto-estigmatización. Experiencias subjetivas de jóvenes de educación secundaria. En C. Kaplan, L. Krotsch \& V. Orce, Con ojos de joven Relaciones entre desigualdad, violencia y condición juvenil (pp. 15-78). Buenos Aires: Editorial de la Facultad de Filosofía y Letras (UBA).

Kaplan, Carina. (2013). El miedo a morir joven. Meditaciones de los estudiantes sobre la condición humana. En C. Kaplan, Culturas estudiantiles: sociología de los vínculos en la escuela (pp. 45-67). Buenos Aires: Miño y Dávila.

Le Breton, David. (2010). Rostros. Buenos Aires: Letra Viva.

Le Breton, David. (2014). Una breve historia de la adolescencia. Buenos Aires: Nueva Visión.

Mejía Hernández, Juana (2013). Relaciones sociales y violencias entre adolescentes de secundaria (Tesis doctoral). Cinvestav del Instituto Politécnico Nacional, México.

Ness, Cindy. (2004). Why Girls Fight: Female Youth Violence in the Inner City. The ANNALS of the American Academy of Political and Social Science, 595(1), 32-48.

Reguillo Cruz, Rossana. (2000). Emergencia de culturas juveniles : estrategias del desencanto. Barcelona: Grupo Editorial Norma.

Sartre, Jean-Paul. (2004). El Ser y la nada. Barcelona: RBA Coleccionables.

Simmel, George. (2011). El rostro y el retrato. Madrid: Casimiro.

Simmel, George. (2014). Sociología: estudios sobre las formas de socialización. México: Fondo de Cultura Económica.

Valles, Miguel. (2002). Entrevistas cualitativas. Madrid: Centro de Investigaciones Sociológicas. 
